\title{
Effects of pregnancy serum and scriptaid on development in early partheno embryo
}

\author{
Min-Gee Oh ${ }^{1, \#}$, Na-Hyeon Jung ${ }^{2, \#}$, Dae-Seung Kim² and Jong-Taek Yoon ${ }^{1, *}$ \\ ${ }^{1}$ Department of Animal Life Science, Hankyong National University, Anseong 17579, Korea \\ ${ }^{2}$ Major in the Animal Biotechnology, Graduate School of Future Convergence Technology, Hankyong National \\ University, Anseong 17579, Korea
}

Received May 13, 2020

Accepted May 14, 2020

\section{*Correspondence \\ Jong-Taek Yoon \\ E-mail: JTyoon@hknu.ac.kr}

\section{ORCID}

https://orcid.org/0000-0002-9408-8239

"These authors contributed equally to this work.

\begin{abstract}
Partheno Embryo's research is known to play a very important role in identifying the development of embryonic cells or analyzing the genetic mechanisms of embryonic development, but the information on apoptosis formed during the early stage of development on Partheno Embryo is very little. Therefore, this study analyzed whether the embryonic cell death of unit embryos can be inhibited by adding Scriptaid, one of HDACi, which plays a role in demethylation of histone proteins as a method of regulating the cell cycle in the early embryo development of Partheno Embryo. As a result, the differentiation rate was higher in the group that added Scriptaid and FBS, but the cellular development was higher in the group that added pregnant serum to Scriptaid. As a result of analyzing the expression of the gene through IF and $\mathrm{PCR}$, the group with the addition of gestational serum increased the expression of BCL2 and PCNA, which affects the anti-Casp3 action in cell survival. In addition, it is interpreted that treatment of Scriptaid for 16 hours, rather than $24 \mathrm{~h}$ treatment lowers the expression of Casp-3, a representative factor of apoptosis, and also increases embryonic development, thus affecting early embryo development. Therefore, it is concluded that the 16-hour treatment of Scriptaid and the use of gestational serum will inhibit cell death in the early embryonic development and increase the development rate of the embryo.
\end{abstract}

Keywords: apoptosis, partheno embryo, porcine, pregnancy serum, scriptaid

\section{INTRODUCTION}

The study of the development of partheno embryos was studied for the purpose of identifying the stages of development of early embryonic cells and stimulating the induction of implantation (Bos-Mikich et al., 2016), and the current study is known to focus on the production of stem cells by autogenous replication (Brevini and Gandolfi, 2008). However, the early development of partheno embryos results in the disruption of metabolism in cell division due to the lack of specific genes in the ancestry (Kim and Lee, 2019), and it is difficult to predict the exact differentiation compared to the development of a normal fertilized embryo (Surani et al., 1984). In the production process of partheno embryo, it consists of a mechanism that controls the activity of mitochondria by forcibly condensing the cytoplasm. Among these mechanisms, it is known to be composed of a diploid by condensation of a second polar body and a combination of the main nucleus. Physical stimulation induces activity in the cytoplasm 
through the gene activation of PKA and PKC through the expansion of $\mathrm{Ca}+$ Channel into the cytoplasm, and this phenomenon is mistaken for the normal nuclear fusion process of sperm and starts cell division (Russo et al., 1996). However, due to the lack of the male gene, the early development of partheno embryos is inhibited in metabolism compared to normal in vitro fertilization, and anomalies due to starvation and external shock of cells are formed, which develop into apoptosis (Cha et al., 1997). The apoptosis mechanism can largely explain two mechanisms of apoptosis and autophagy. Among them, the apoptotic phenomenon, which is an internal necrosis action, is representative, and it can be regarded as a basic apoptosis process due to the starvation state and external impact of the cells (Lee et al., 2011). Particularly, due to the nature of partheno embryo, physical stimulation is known to induce cell death by controlling the metabolic action of mitochondria in the cell cycle. And the action of IGF2 is inhibited in the HDACi conjugate composition, causing starvation of the cell (Elahi et al., 2018; Lee et al., 2018).

In addition, it is thought that the activity of Caspase- 3 plays a direct role in apoptosis due to the formation of an apoptotic complex (Ryu and Yoon, 2018). In other words, the inhibition of the development of partheno embryos can be judged to be accelerated by apoptosis, as the occurrence of metabolic stimulating factors that are formed in the early or middle of cell division is inhibited by external apoptosis stimulating factors. According to a recent study as a control method for such a phenomenon, the use of scriptaid is suggested as a way to increase the metabolic process by facilitating the generation of embryonic cells in the cell division process (Diao et al., 2013; Jungmin et al., 2013). Scriptaid is a HDACi (Histone Deacetylase inhibitor) that affects various processes such as growth retardation, differentiation, cytotoxicity, and apoptosis, and modifies the expression of abnormally expressed genes (Yang et al., 2014). It is also known to increase the action of IGF signal necessary for cell growth by acetylating Histone protein, which maximizes embryo development (Duncan et al., 2017). This study is to determine whether the action of scriptaid may inhibit the cell death process in the early development of unit embryos, and in the in vitro culture process, using normal serum and serum of the early gestation period, maximizing the mechanism of metabolism.

\section{MATERIALS AND METHODS}

\section{Chemicals and animal ethics statement}

All chemicals used in this study were purchased from the Sigma-Aldrich Chemical Company (St. Louis, MO, USA), unless otherwise stated. This study was carried out in strict accordance with the recommendations in the Guide for the Care and Use of Laboratory Animals of the National Institutes of Health. The protocol was approved by the Committee on the Ethics of Animal Experiments of Hankyong National University (Permit Number: 2018, 2018-002).

\section{In vitro maturation}

Porcine ovaries were collected at local abattoirs (DODRAM, Ansoung, Korea) and transported to the laboratory in $0.9 \%$ physiological saline (with Penicillin G 100 $\mathrm{IU} / \mathrm{mL}$, Streptomycin $100 \mu \mathrm{g} / \mathrm{mL}$ ) at $37^{\circ} \mathrm{C}$ within $2 \mathrm{hr}$ of slaughter. Cumulus-oocyte complexes (COC) were aspirated from surface ovarian follicles 3-6 $\mathrm{mm}$ in diameter using an 18-gauge needle attached to a $10-\mathrm{mL}$ disposable syringe. The supernatant was removed and the precipitate washed three times in a wash medium containing Hepesbuffered tissue culture medium 199 (TCM-199), $10 \mu \mathrm{L} / \mathrm{mL}$ antibiotic and $0.3 \%(\mathrm{w} / \mathrm{v})$ bovine serum albumin (BSA). Selected COCs were transferred to $500 \mu \mathrm{L}$ of IVM medium, which was supplemented with $10 \%$ (v/v) FBS, $15 \mathrm{ng} / \mathrm{mL}$ epidermal growth factor (EGF), $10 \mathrm{IU} / \mathrm{mL}$ pregnant mare serum gonadotropin 199 (PMSG) and human chorionic gonadotropin (hCG), and $30 \mu \mathrm{g} / \mathrm{mL}$ kanamycin for 20-22 hours. After maturation with hormones, COCs were incubated in hormone-free IVM medium at $39^{\circ} \mathrm{C}$. for an additional 21-22 hours in humidified air containing $5 \% \mathrm{CO}_{2}$.

\section{Parthenogenetic activation}

After a 44 hours IVM period, oocytes were released from follicle cells by treatment with $0.1 \%$ hyaluronidase. The removed oocytes were washed several times in an activation solution (0.28 M D-mannitol, $0.1 \mathrm{mM} \mathrm{MgSO}_{4}, 0.05$ $\mathrm{mM} \mathrm{CaCl}{ }_{2}$ and $0.01 \% \mathrm{BSA}$ ) and then activated with a direct current chemical stimulus at $7 \mathrm{~min}$ using $7 \%$ ethanol. After oocytes activation was induced for 2 hours in $2 \mathrm{mM}$ 6-DMAP (6-dimethylaminopurine), and then stabilized by incubating for 4 hours in $2 \mathrm{Mm} \mathrm{H}$-DSOF (HEPES-buffered synthetic oviduct fluid) to promote cell development. 


\section{In vitro culture}

For experiments using in-vitro culture, we prepared three types of in-vitro culture media: FBS group medium is the NCSU-23 medium (North Carolina State University 23 medium) contained 10\% FBS (Petters and Wells, 1993), PS group medium is the NCSU-23 medium contained 10\% Pregnancy serum (Cow blood serum after 30 days of pregnancy), scriptaid was added to $1 \mathrm{mM}$ and incubated for 16 hours or 24 hours, respectively, and then replaced with a scriptaid free medium. Ten zygotes were added to $30 \mu \mathrm{L}$ drop of each type of prepared medium and covered with mineral oil, incubated at $39^{\circ} \mathrm{C}$ for 4 days in $5 \%$ $\mathrm{CO}_{2}$, humid atmosphere. The zygotes were incubated for 3 days, then transferred to freshly prepared culture medium. Subsequently, cell division rates were evaluated on culture days 2, 3 and 4, respectively (Visual analysis was performed according to the methods of Alikani et al., 1999 and Mateusen et al., 2005).

\section{Enzyme linked immunosorbent assay}

For ELISA, total protein was extracted from parthenogenesis embryo using Pro-Prep solution (Intron) according to the manufacturer's instructions. Total protein was quantified using the Bradford Protein Assay Kit (Bio-Rad). For quantification of specific proteins from culture medium and cellular proteins, samples diluted in assay buffer were used to coat a 96-well ELISA plate overnight at $4^{\circ} \mathrm{C}$. MT1-MM (sc-30074, Santa Cruz Biotechnology Inc., Texas, USA), MMP-2 (ab78796-100, Abcam, Cambridge, UK) and MMP-9 (sc-13520, Santa Cruz Biotechnology Inc., Texas, USA) primary antibodies were added to 96well ELISA plates to analyze the expression levels these proteins in protein sample and culture media; incubation was conducted at $4^{\circ} \mathrm{C}$ for 24 hours. After washing twice with wash buffer $(1 \times$ PBS containing $2.5 \%$ Triton X-100), well contents were blocked for 24 hours at $4{ }^{\circ} \mathrm{C}$. with $1 \%$ skim milk blocking solution. After washing with wash buffer, anti-rabbit (sc-2054, Santa Cruz Biotechnology, Texas, USA) and anti-mouse (sc-2054 and sc-2031, Santa Cruz Biotechnology, Texas, USA) were added secondary antibodies. Each well, and plate were incubated for 2 hours with detection or substrate solution ( $\mathrm{R} \& \mathrm{D}$ Systems, USA). The reaction was stopped with $1 \mathrm{M} \mathrm{NH}_{2} \mathrm{SO}_{4}$, and absorbency was measured at $450 \mathrm{nM}$.

\section{Zymography}

In vitro culture medium is added to Foz loading buffer (0.06\% bromophenol, $10 \%$ SDS, $2 \%$ glycerol), left on ice for 5 minutes, and then electrophoresed at $150 \mathrm{~V}$ for 1 hour 30 minutes; A 12\% SDS-PAGE gel containing $100 \mathrm{mg} / \mathrm{mL}$ gelatin A/B was used. The gel was washed twice with reconstruction buffer $(2.5 \%$ Triton X-100) for 20 minutes, then placed in a zymography reaction buffer and incubated at $37^{\circ} \mathrm{C}$ for 18 hours. Then, the gels were stained $(0.5 \%$ Coomassie Blue R250 (Bio-rad, USA)) for measurement of white band to MMP-2 and MMP-9 activity. Average fold values for all hormones were measured and are expressed as mean \pm standard deviation. Data were analyzed using t-test and generalized linear model method using SPSS Statistics 20 (SPSS, Korea).

\section{Semi-quantitative polymerase chain reaction}

RNA from parthenogenetic embryos was isolated by adding TRIzol reagent directly. Following cell lysis, total cellular RNA was isolated according to the manufacturer's instructions. The final RNA precipitate was resuspended in double-distilled water containing $0.1 \%$ diethyl pyrocarbonate (DEPC), and the RNA samples were stored at $-80^{\circ} \mathrm{C}$ until use. First-strand cDNA was synthesized by reverse transcription of mRNA using Oligo(dT) primer and SuperScript II Reverse Transcriptase (Invitrogen, Grand Island, NY). SQ PCR amplification was performed with target gene primers (Table 1) and 18Sr (housekeeping gene) primer with an annealing temperature of $51-65^{\circ} \mathrm{C}$ and 30 cycles.

\section{Immunofluorescence}

Each samples were fixed in $4 \%$ paraformaldehyde overnight at $4^{\circ} \mathrm{C}$, after, washed for $20 \mathrm{~min}$ in $1 \mathrm{xPBS}$, and permeabilized with $0.2 \%$ Triton X-100 for 30 min at room temperature (RT). And blocking with 3\% BSA in PBS, the samples were incubated with an antibody against the active forms of Casp-3 (ab4051, abcam, Combridge, UK) and PCNA (sc-7907, Santa Cruz Biotechnology Inc., Texas, USA) at 1:200 dilutions. The samples were then washed and incubated with anti-rabbit (35560) and anti-mouse IgG (A11001) conjugated to Alexa Fluor 488 or Alexa Fluor 594 (Molecular Probes: Invitrogen, Ontario, Canada). Nuclei were counterstained with $1 \mathrm{~g} / \mathrm{mL}$ Hoechst 33258, and cover slips were mounted using fluorescent mounting medium (Dako, Carpinteria, CA). Images were acquired using 
Table 1. Primers for SQ-PCR analysis of cell survival and apoptosis associated genes

\begin{tabular}{|c|c|c|c|}
\hline No. & Name & & Sequence \\
\hline \multirow[t]{2}{*}{1} & GAPDH & Forward & 5'-CCC GTT CGA CAG ACA GCC GTG-3' \\
\hline & & Reverse & 5'-CCG CCT TGA CTG TGC CGT GG-3' \\
\hline \multirow[t]{2}{*}{2} & E2-r & Forward & $5^{\prime}-\mathrm{ACA}$ AGC GCC AGA GAG AGA TGA T-3' \\
\hline & & Reverse & 5'-AGG ATC TCT AGC CAG GCA CA-3' \\
\hline \multirow[t]{2}{*}{3} & EGF & Left & 5'-CCA GGG GTC TCT TCT CCA AG-3' \\
\hline & & Right & 5'-GGT GGG AAT GTA AAC TGG TA-3' \\
\hline \multirow[t]{2}{*}{4} & IGF & Left & 5'-CTC TTC GCA TCT CTT CTA C-3' \\
\hline & & Right & 5'-CAA ATG TAC TTC CTT CTG AG-3' \\
\hline \multirow[t]{2}{*}{5} & AKT1 & Forward & 5'-GGT CAT GTA CGA GAT GAT GTG CGG C-3' \\
\hline & & Reverse & $5^{\prime}-\mathrm{CTT}$ GAA CGG TGG GCT GAG CTT CTT C-3' \\
\hline \multirow[t]{2}{*}{6} & mTOR & Forward & $5^{\prime}-\mathrm{CTT}$ TGT CCA GAC CAT GCA GCA GC-3' \\
\hline & & Reverse & 5'-TCG TTG ATG CCC TGT AGG TTC AGC-3' \\
\hline \multirow[t]{2}{*}{7} & PCNA & Forward & 5'-GCA CTG AGG TAC CTG AAC TT-3' \\
\hline & & Reverse & 5'-TCT TCA TCC TCG ATC TTG GG-3' \\
\hline \multirow[t]{2}{*}{8} & $\mathrm{BCL}-2$ & Forward & 5'-CCA GGC CGG CGA TGA CTT CTC T-3' \\
\hline & & Reverse & 5'-ATC TCC CGG TTG ACG CTC TCC ACA-3' \\
\hline \multirow[t]{2}{*}{9} & BAX & Forward & 5'-ATG GAC GGG TCC GGG GAG CAA-3' \\
\hline & & Reverse & 5'-TCA GCC CAT CTT CTT CCA GAT-3' \\
\hline \multirow[t]{2}{*}{10} & $20 \mathrm{a}-\mathrm{HSD}$ & Forward & 5'-ACC ACA GTC CAT GCC ATC AC-3' \\
\hline & & Reverse & 5'-TCC ACC ACC CTG TTTG CTG TA-3' \\
\hline \multirow[t]{2}{*}{11} & Casp-3 & Forward & 5'-CAT GGT CAG GCC TTG TGA AGC TGA-3' \\
\hline & & Reverse & 5'-TCT TCT TCA TGA CCT GAC CGT CGG-3' \\
\hline
\end{tabular}

an Olympus AX70 fluorescence microscope fitted with a CCD color camera.

\section{Statistical analyses}

The real-time RT-PCR results were analyzed for statistical significance using the SAS package (version 9.4; Statistical Analysis System Institute, Cary, NC, USA). Data were subjected to Welch's t-test, fold change, and GLM in SAS. Data are the mean $\pm S D$, and differences between groups were considered significant when $p$ values were less than 0.05 .

\section{RESULTS}

\section{Changes in embryonic cells during in vitro culture}

The FBS group showed higher development rate than the pregnancy serum group, and the Scriptaid treated for $16 \mathrm{hr}$ group had a higher development rate than the Scriptaid treated for $24 \mathrm{hr}$ group (Table 2).

In addition, in the treatment of Scriptaid was higher cytoplasm degradation in the $24 \mathrm{hr}$ treatment group compared to the $16 \mathrm{hr}$ treatment group.
Table 2. Cleavage rate of partheno embryos

\begin{tabular}{lcccc}
\hline \multicolumn{1}{c}{ Group } & No. of oocyte & $\mathbf{2}$ 2-cell (\%) & $\mathbf{2}$ 4-cell (\%) & $\mathbf{\geq}$ 8-cell (\%) \\
\hline FBS & 183 & $15(8.19)$ & $15(8.19)$ & $15(8.19)$ \\
PS & 174 & $6(3.45)$ & $6(3.45)$ & - \\
FBS-16 & 166 & $64(38.55)^{\mathrm{c}}$ & $53(31.93)^{\mathrm{b}}$ & $42(25.30)^{\mathrm{a}}$ \\
PS-16 & 165 & $48(29.09)^{\mathrm{b}}$ & $36(21.82)^{\mathrm{a}}$ & $21(12.73)$ \\
FBS-24 & 181 & $51(28.18)^{\mathrm{b}}$ & $46(25.14)^{\mathrm{a} b \mathrm{~b}}$ & $33(18.23)^{\mathrm{a}}$ \\
PS-24 & 140 & $28(20.00)^{\mathrm{a}}$ & $20(14.29)$ & $16(11.43)$ \\
\hline
\end{tabular}

FBS: Follicular stimulation hormone treat, PS: Bovine pregnancy serum. a,b,c Different letters within same column represent a significant difference $(p<0.05)$

On the other hand, when Scriptaid was treated with pregnancy serum, it was confirmed that the increase in the degradation were suppressed than when using FBS. In particular, the group treated with Scriptaid $16 \mathrm{hr}$ and pregnancy serum showed a decrease in degradation compared to the group treated only with pregnancy serum (Fig. 1).

\section{MMPs expression in embryonic cells}

When the scriptaid treatment time was $24 \mathrm{hr}$, the expression of MT1-MMP increased slightly, while in the case of MMP-2, it tended to decrease, but it did not show a significant difference and showed similar overall expression level. The activity of MMPs was different depending on the exposure time of the scriptaid and the type of serum. In particular, in the group using FBS with scriptaid treatment, the activity of active MMP-9 was low, and the activity of MMP-2 was high.

On the other hand, in the group supplemented with scriptaid and pregnancy serum, the activity of MMP-9 dimer was shown, and the activity of MMP-2 was slightly lower than that of the FBS added group (Fig. 2).

\section{Analysis of gene expression patterns related to cell survival and apoptosis}

In the case of PCNA and E2-r, factors related to cell survival, high expression was observed in the pregnancy serum group treated with $16 \mathrm{hr}$ scriptaid. In addition, the anti-apoptosis factor BCL-2 was the highest in the $16 \mathrm{hr}$ scriptaid treated pregnancy serum group, and the expression of BAX was lower than from the other groups (Fig. 3). As a result of analyzing the expression of Casp3 and PCNA through IF, the expression of Casp-3 in the cytoplasm was high in the group treated with scriptaid. 

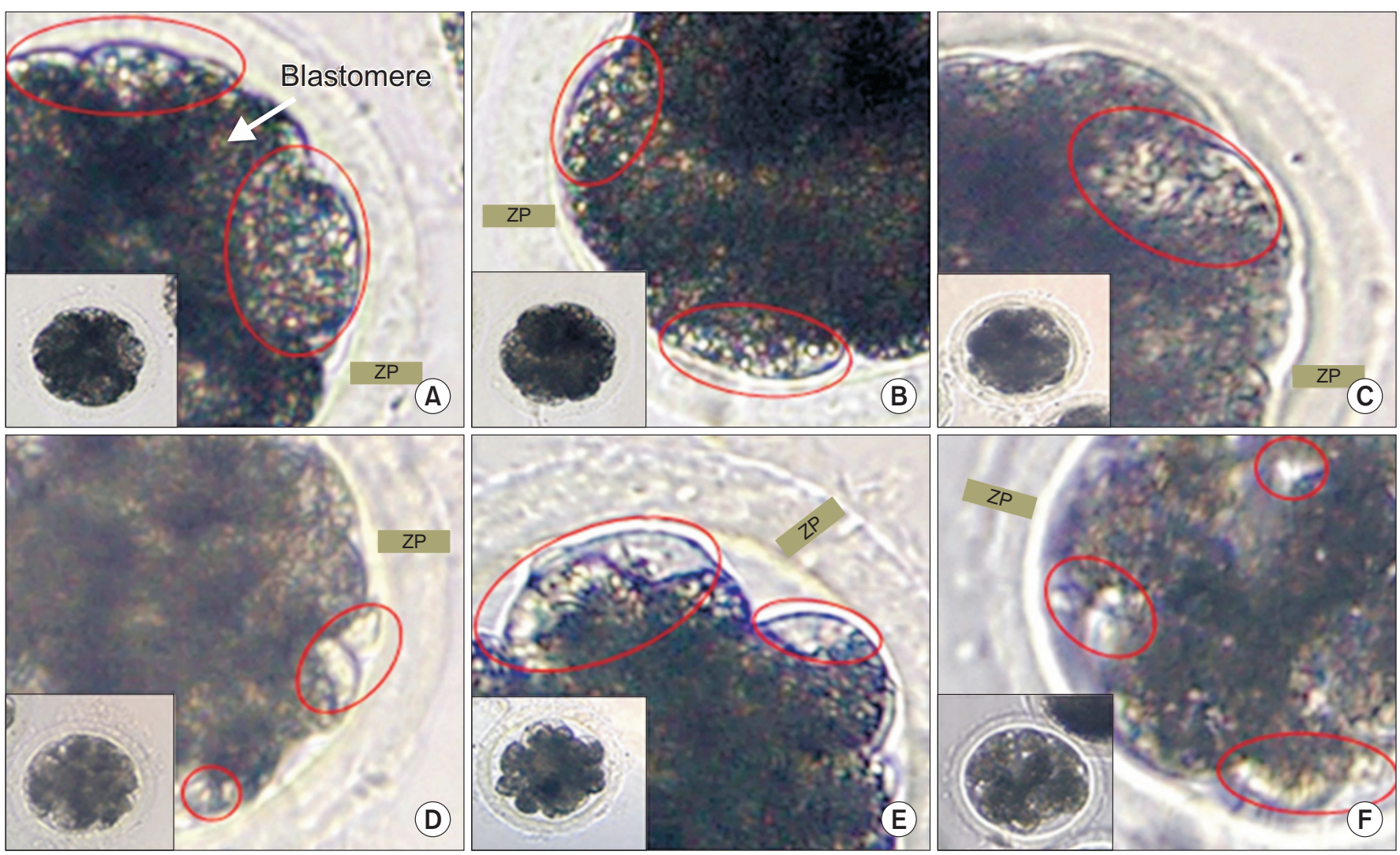

Fig. 1. Development and cytoplasm quality of parthenogenetic embryo. In this figure, applied different filter. (A) FBS group. (B) Pregnancy serum group. (C) FBS and $16 \mathrm{hr}$ scriptaid. (D) Pregnancy serum and $16 \mathrm{hr}$ scriptaid. (E) FBS and $24 \mathrm{hr}$ scriptaid. (F) Pregnancy serum and $24 \mathrm{hr}$ scriptaid. ZP: Zona pellucida, Red round: degradation of cytoplasm $(\times 200)$.

On the other hand, the group using pregnancy serum increased the expression in the cytoplasm while maintaining the PCNA expression in the zona pellucida when the scriptaid was processed together. In particular, when used together with the $16 \mathrm{hr}$ scriptaid treatment, the expression of strong PCNA and the expression of low casp3 (Fig. 4).

\section{DISCUSSION}

Research on the development of partheno embryos has been conducted for the purpose of identifying the stages of development of early embryonic cells and stimulation of implantation induction (Bos-Mikich et al., 2016), and it is known to be focusing on stem cell production by autogenous replication recently (Brevini and Gandolfi, 2008). However, it is a common phenomenon that a partheno embryo does not induce implantation due to the absence of specific genetic action of the paternal line (Surani et al., 1984). Particularly, in the early embryonic development, the development of the partheno embryo is lower than that of the normal fertilized embryo, thereby increasing the mechanism of cell death due to starvation (Cha, 1997). In this study, we observed the abnormality of cells in the early embryonic development period of the partheno embryo, also, analyzed whether serum changes and Scriptaid, which plays a role in the demethylation of histone proteins in the cell cycle, can control the starvation and apoptosis. As a result of analyzing the normality of partheno embryo cells, this study confirmed that the difference in serum affects the differentiation process of partheno embryo differently. In the case of partheno embryos induced differentiation using FBS, the development rate of blastomere was relatively low, and particularly, it was confirmed that degradation were highly formed between the cytoplasm and the cell membrane. However, in the case of partheno embryos cultured using pregnency serum, it was confirmed that differentiation and fidelity of the cytoplasm increased (Jung et al., 2020).

The results of this study suggest that the addition of 


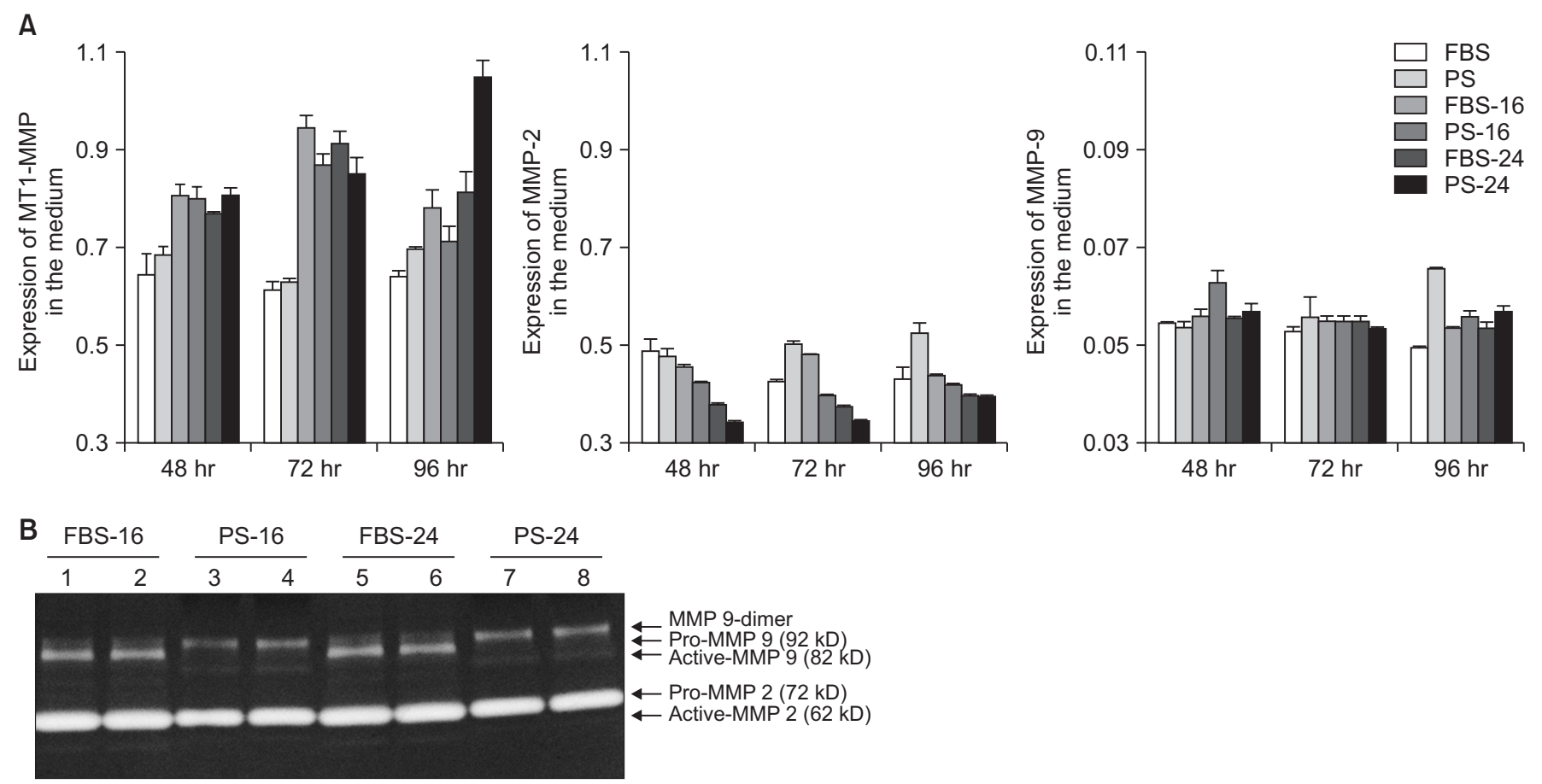

Fig. 2. Analysis of matrix metalloproteinase (MMP) expression and activity in culture medium. (A) ELISA analysis, FBS: FBS group, PS: pregnancy serum group, FBS-16: FBS and $16 \mathrm{hr}$ scriptaid, PS-16: pregnancy serum and $16 \mathrm{hr}$ scriptaid, FBS-24: FBS and 24 hr scriptaid, PS-24: pregnancy serum and $24 \mathrm{hr}$ scriptaid. (B) Gelatin Zymography analysis, 1: FBS-16 48 hr media, 2: FBS-16 96 hr media, 3: PS-16 48 hr media, 4: PS-16 96 hr media, 5: FBS-24 48 hr media, 6: FBS-24 96 hr media, 7: FBS-24 48 hr media, $8:$ FBS-24 96 hr media.

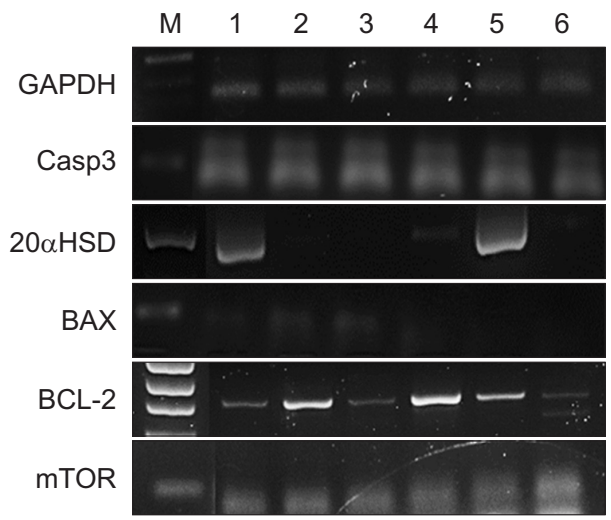

pregnency serum is thought to increase the development of the cytoplasm, and it is confirmed that it can induce the activity of the cytoplasm during early embryo differentiation (Jungmin et al., 2013). In the case of pregnancy serum, it can be seen that the action of unknown growth factors or hormones is increased compared to normal serum (Hafez and Hafez, 2006), and that metabolic effects on embryonic development may be different from. As in the study that the development and differentiation of the cytoplasm is promoted by the action of MMPs during embryonic development (Kim and Yoon, 2018), the addition of scriptaid increases the action of MMPs as a result of increasing the activity of Histone protein. It has been shown to promote the development of cytoplasm, and can be seen to minimize the basic death process due to the starvation and external impact of the cells. In addition, the disruption of cell survival factors according to the embryonic cell differentiation process in the process of generating embryos (Park et al., 2017) can be reduced by the use of pregnency serum and scriptaid. In particular, 


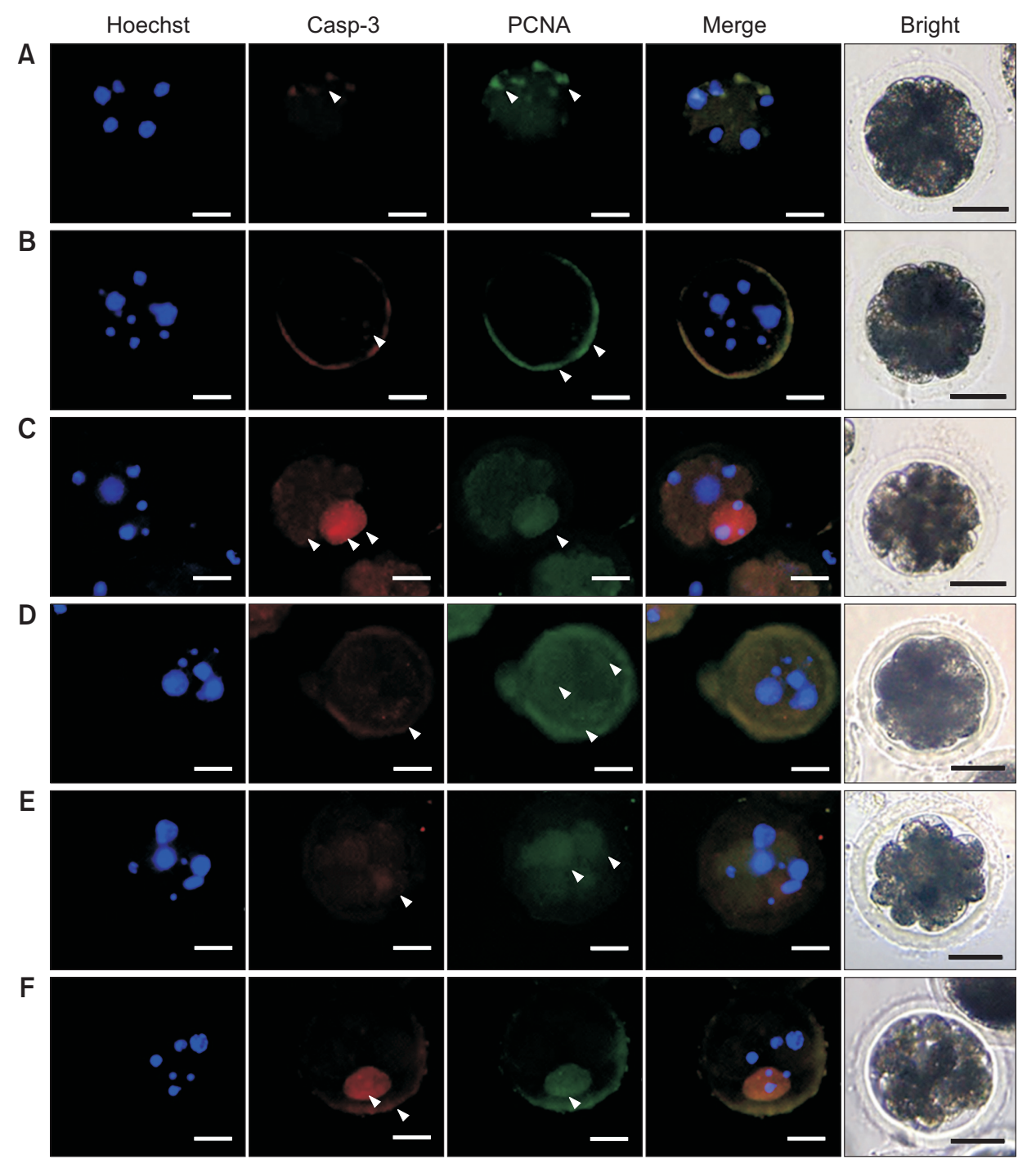

Fig. 4. Expression site and surface analysis of Casp-3 and PCNA in parthenogenetic embryo. (A) FBS group. (B) Pregnancy serum group. (C) FBS and $16 \mathrm{hr}$ scriptaid. (D) Pregnancy serum and $16 \mathrm{hr}$ scriptaid. (E) FBS and $24 \mathrm{hr}$ scriptaid. (F) Pregnancy serum and $24 \mathrm{hr}$ scriptaid (bar $=50 \mu \mathrm{m}$ ).

it is thought that the PCNA acting upon cell differentiation increases in the cytoplasm, and the activity of Casp3 can be suppressed. Therefore, as a way to induce stable division of embryonic cells in the early development of partheno embryos, it is thought that the use of pregnancy serum promotes cell development and the addition of scriptaid suppresses starvation by increasing metabolic processes of cells. The results of this study suggest new methods for the generation of partheno embryos, and this is thought to be a very important research result in embryonic cell construction for embryo transfer or autologous stem cell production.

\section{CONFLICTS OF INTEREST}

No potential conflict of interest relevant to this article was reported.

\section{AUTHOR CONTRIBUTIONS}

Conceptualization: MG Oh, NH Jung, JT Yoon. Data curation: MG Oh. Formal analysis: MG Oh, NH Jung, DS Kim. Funding acquisition: JT Yoon. Investigation: MG Oh, DS Kim. Methodology: MG Oh, NH Jung, DS Kim. Project administration: MG Oh, JT Yoon. Resources: MG Oh, JT Yoon. Supervision: JT Yoon. Roles/Writing - original draft: MG Oh, NH Jung. Writing - review \& editing: MG Oh, JT Yoon. 


\section{AUTHOR'S POSITION AND ORCID NO.}

\author{
MG Oh, Student, \\ https://orcid.org/0000-0002-9289-3779 \\ $\mathrm{NH}$ Jung, Researcher, \\ https://orcid.org/0000-0003-3073-960X \\ DS Kim, Ph.D Student, \\ https://orcid.org/0000-0002-5740-9136 \\ JT Yoon, Professor, \\ https://orcid.org/0000-0002-9408-8239
}

\section{REFERENCES}

Bos-Mikich A, Bressan FF, Ruggeri RR, Watanabe Y, Meirelles FV. 2016. Parthenogenesis and human assisted reproduction. Stem Cells Int. 2016:1970843.

Brevini TA and Gandolfi F. 2008. Parthenotes as a source of embryonic stem cells. Cell Prolif. 41(Suppl 1):20-30.

Cha SK, Kim NH, Lee SM, Baik CS, Lee HT, Chung KS. 1997. Effect of cytochalasin $\mathrm{B}$ and cycloheximide on the activation rate, chromosome constituent and in vitro development of porcine oocytes following parthenogenetic stimulation. Reprod. Fertil. Dev. 9:441-446.

Diao YF, Naruse KJ, Han RX, Li XX, Oqani RK, Lin T, Jin DI. 2013. Treatment of fetal fibroblasts with DNA methylation inhibitors and/or histone deacetylase inhibitors improves the development of porcine nuclear transfer-derived embryos. Anim. Reprod. Sci. 141:164-171.

Duncan HF, Smith AJ, Fleming GJ, Reid C, Smith G, Cooper PR. 2017. Release of bio-active dentine extracellular matrix components by histone deacetylase inhibitors (HDACi). Int. Endod. J. 50:24-38.

Elahi F, Shin H, Lee J, Lee ST, Lee GS, Lee E. 2018. Exogenous nitric oxide donation during in vitro maturation improves embryonic development after parthenogenesis and somatic cell nuclear transfer in pigs. J. Emb. Trans. 33:211-220.

Hafez ESE and Hafez B. 2006. Reproduction in Farm Animals. 7th ed, Wiley-Blackwell, Ames, pp. 68-81.

Jung NH, Kim SH, Kim DS, Yoon JT. 2020. Study on the in-vitro culture method for normal embryonic cell development of porcine parthenogenetic embryos. J. Anim. Reprod. Biotechnol. 35:94-101.

Kim CJ and Lee KB. 2019. Effect of paternal DNA damage on paternal DNA degradation and early embryonic development in mouse embryo: supporting evidence by gammaH2AX expression. J. Anim. Reprod. Biotechnol. 34:197-204.

Kim SH and Yoon JT. 2018. Effects of MMP-2 activation and FSH or LH hormone supplementation on embryo development in in vitro fertilization of porcine. J. Emb. Trans. 33:313-319.

Lee J, Lee Y, Jung HH, Lee ST, Lee GS, Lee E. 2018. Effect of glycine and various osmolarities of culture medium on in vitro development of parthenogenesis and somatic cell nuclear transfer embryos in pigs. J. Emb. Trans. 33:221-228.

Lee SE, Hwang KC, Sun SC, Xu YN, Kim NH. 2011. Modulation of autophagy influences development and apoptosis in mouse embryos developing in vitro. Mol. Reprod. Dev. 78:498-509.

Mateusen B, Van Soom A, Maes DG, Donnay I, Duchateau L, Lequarre AS. 2005. Porcine embryo development and fragmentation and their relation to apoptotic markers: a cinematographic and confocal laser scanning microscopic study. Reproduction 129:443-452.

Park HB, Park YR, Lee HY, Bae HK, Lee S, Park CK, Yang BK, Cheong HT. 2017. Endoplasmic reticulum (ER) stress and apoptosis in parthenogenetic porcine embryos following different combination of activation methods. J. Emb. Trans. 32:25-31.

Russo GL, Kyozuka K, Antonazzo L, Tosti E, Dale B. 1996. Maturation promoting factor in ascidian oocytes is regulated by different intracellular signals at meiosis I and II. Development 122:1995-2003.

Ryu JE and Yoon JT. 2018. Analysis of apoptosis on the somatic cell nuclear transfer embryos in porcine. J. Emb. Trans. 33:119-127.

Surani MA, Barton SC, Norris ML. 1984. Development of reconstituted mouse eggs suggests imprinting of the genome during gametogenesis. Nature 308:548-550.

Yang Y, Han X, Guan J, Li X. 2014. Regulation and function of histone acetyltransferase MOF. Front. Med. 8:79-83. 